accurate in each data system to better than $1 \mathrm{~s}$ during the period of the measurements.

The time during which the cable measurements were made was relatively quiet geomagnetically ${ }^{8}$. Five of the most quiet days were selected to represent the $S_{\mathrm{q}}$ variation measured at Green Hill. These days, and their daily sum global geomagnetic activity indices $\Sigma K_{\mathrm{p}}$ were: 3 May, $-6 ; 4$ May, $-9 ; 5$ May, -14 ; $17 \mathrm{May},+5 ; 18 \mathrm{May},-8$. The averages of these five quiet days in the three magnetic field components measured at Green Hill are shown as solid lines in Fig. 2. These averages are obtained from the hourly mean values. The time dependences during a day show typical $S_{\mathrm{q}}$ patterns for this geomagnetic latitude, except for the local morning intervals in the $H$ - and $Z$-components.

The dashed lines in Fig. 2 show the computed $S_{\mathrm{q}}$ curves expected on the basis of the spherical harmonic analysis of the potential for the daily variation by Chapman and Bartels ${ }^{9}$. We used the harmonic coefficients of Matsushita ${ }^{10}$ for location B on the model cable path in Fig. 1. The fit of the calculated $S_{\mathrm{q}}$ patterns using location $B$ is quite good in the east-west component but is not good for the local morning observations in either the north-south or the vertical components. In addition, the magnitude of the $S_{\mathrm{q}}$ variation observed in the local afternoon in the north-south component is about a factor of two larger than that predicted by the model $S_{q}$ calculations. These disagreements in the north-south and vertical components are

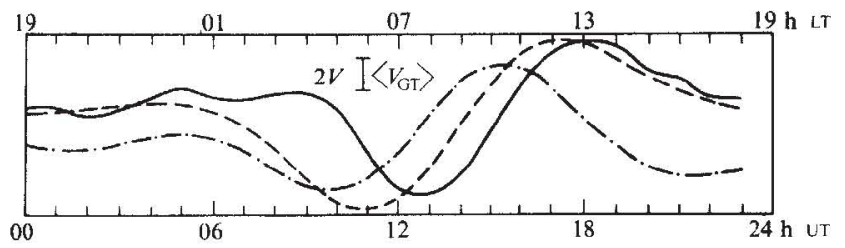

Fig. 3 Average of cable voltage variation for the five geomagnetic quiet days (solid line). Calculated induced voltage from all three magnetic components produced by $S_{\mathrm{q}}$ current system (dashed line). Calculated induced voltage from the horizontal magnetic component produced by $S_{\mathrm{q}}$ current system (dot-dashed line).

partially due to the closeness of the measurement site $(\sim 3 \mathrm{~km})$ to the North Atlantic Ocean as well as to uncertainties in the spherical harmonic coefficients used in the $S_{\mathrm{q}}$ calculations. Note that data (not shown here) from our magnetometer station at Durham, New Hampshire, $\left(44^{\circ} \mathrm{N}, 72^{\circ} \mathrm{W}\right.$ geographic), located $\sim 30-35 \mathrm{~km}$ from the ocean, show better agreement in the north-south component for the local morning $S_{\mathrm{q}}$ variations than do the Green Hill data.

The solid line in Fig. 3 shows the measured average variation of the cable voltage as a function of local time for the same five days as the magnetic field data of Fig. 2. This average was made using the hourly mean values and computing from them the five day average, in the same manner as was done for the $S_{\mathrm{q}}$ curves of Fig. 2. The relative expected induced voltage from induction by the $S_{\mathrm{q}}$ current system was modelled by considering the universal time (UT) change in the instantaneous $S_{\mathrm{q}}$ magnetic field pattern observed across the cable. To simplify the analysis, the $S_{\mathrm{q}}$ patterns at six locations (A-F in Fig. 1) were used for each hour of UT; the time derivative of the $S_{\mathrm{q}}$ magnetic field pattern was calculated at each of the six points. These six voltages $(V=$ $-\mathrm{d} \Phi(B) / d t$, where $\Phi=\mathbf{B} \cdot \mathbf{n} \boldsymbol{A}$ is the magnetic flux through the surface $S$ with area $A$ ) were averaged to represent the induced voltage across the cable at a given time. This induced voltage is of opposite polarity to the measured voltage. These calculated relative voltages (with changed signs) are superimposed on the measured voltage in Fig. 3. The dashed line is the calculated relative induction considering the total magnetic field changes from the $S_{\mathrm{q}}$ magnetic field pattern in all three components; that is, the total field contribution. The dot-dashed line is the calculated relative voltage considering only the horizontal component. The relative behaviour of this former calculated profile is a reasonably good approximation (with a 1 - to 2-h phase shift) to the observed voltage. (Induction currents from possible tidal ${ }^{2,11,13,14}$ and ocean current ${ }^{12}$ effects are not considered important for this work ${ }^{2,11}$.) A better agreement in terms of phase is obtained by assuming that the induction process that changes the Green Hill voltage occurs closer to the Green Hill end, rather than along the entire length of cable. Calculations of the $S_{\mathrm{q}}$ voltage pattern from points A-D (Fig. 1) show no phase shift. Physical understanding of this effect could be obtained by simultaneous measurements at both Green Hill and St Hilaire.

It is not possible to compare the magnitudes of the calculated voltage values with the observed $S_{\mathrm{q}}$ induced voltage without making some assumption as to the area of the Earth through which the induction process operates. An approximate equality between the relative calculated amplitudes and the observed induced voltage $(\sim 5 \mathrm{~V})$ from the $S_{\mathrm{q}}$ pattern would imply an area of $\sim 10^{12} \mathrm{~m}^{2}$ influenced by the induction.

Future work on induction by shorter-period geomagnetic variations should result in a better understanding of the geomagnetic induction phenomenon in varying geomagnetic conditions as well as at the different Earth locations over which a cable is laid.

We thank S. T. Brewer, B. H. Hamilton, and G. R. Ostby for advice and technical assistance, also G. Hailey and R. Foran for their support and help with our instrumentation at the Green Hill Terminal, and $\mathrm{H}$. Wilhelmsen for his careful reading of the manuscript.

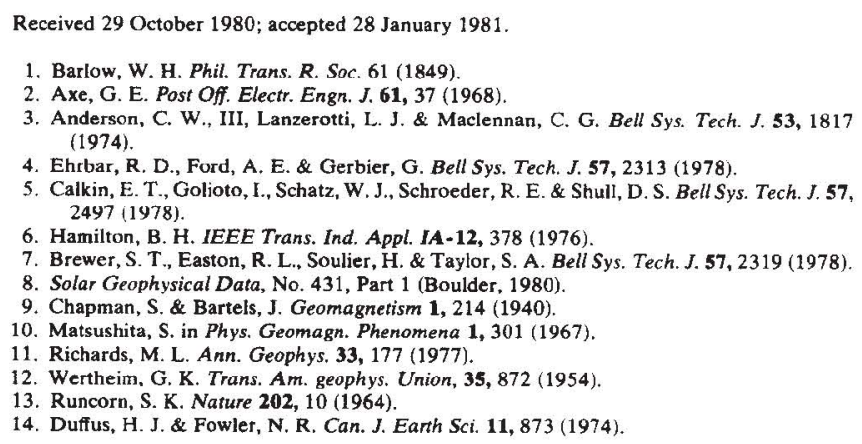

\section{Palaeomagnetic determination of emplacement temperature of Vesuvius AD 79 pyroclastic deposits}

\section{Dennis V. Kent*, Dragoslav Ninkovich*, Tullio Pescatore $\dagger \&$ Stephen R. J. Sparks $\ddagger$}

*Lamont-Doherty Geological Observatory, Palisades, New York 10964, USA

tInstitute of Geology and Geophysics, University of Naples, 80138, Naples, Italy

$\ddagger$ Department of Earth Sciences, University of Cambridge,

Cambridge CB2 3EW, UK

The city of Herculaneum was burried under $20 \mathrm{~m}$ of pyroclastic deposits during the AD 79 eruption of Vesuvius, whose crater is only $7 \mathrm{~km}$ to the east. These deposits have been interpreted as the deposits of mudfiows ${ }^{1}$ or hot pyroclastic flows ${ }^{2-5}$. Maury's studies $^{6}$ of incinerated wood in Herculaneum demonstrate heating to at least $400^{\circ} \mathrm{C}$. We have studied the variation of remanent magnetism with temperature for specimens taken from the deposits, including specimens of the matrix material and of embedded lithic fragments. We conclude that the temperature of the deposit at emplacement is unlikely to have been greater than $400^{\circ} \mathrm{C}$, which further supports the interpretation of the pyroclastic deposits at Herculaneum as largely ignimbrites (hot pyroclastic flow deposits).

Ten oriented drill-core samples were collected from an excavation wall in the pyroclastic flow deposits at the western end of Herculaneum. The unit sampled is typical of the deposits 


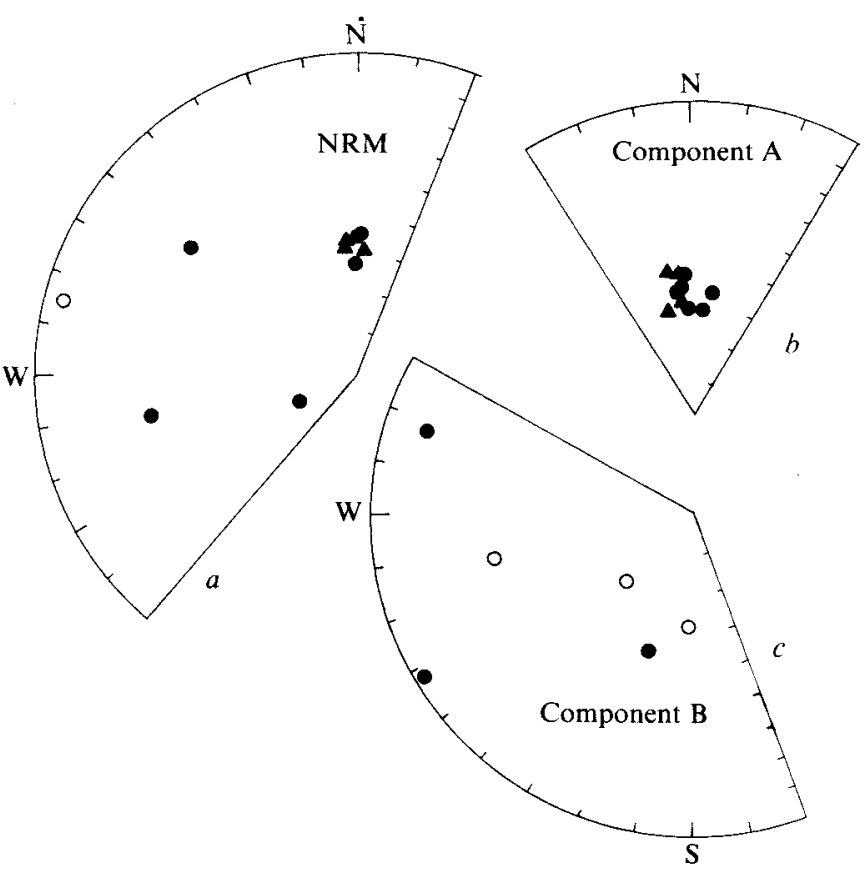

Fig. 1. Palaeomagnetic directions of pyroclastic samples from Herculaneum plotted on segments of equal-area projections. $a$, NRM directions; $b$, A components in lithic clast samples (O) and $400^{\circ} \mathrm{C}$ thermally demagnetized NRM of matrix samples (A); c, B components in lithic clasts (closed symbols on lower, open symbols on upper hemisphere of projection). Present geomagnetic field direction at sampling locality is $\operatorname{dec}=359^{\circ}$; inc $=55^{\circ}$.

which bury the town and appears homogeneous and unstratified, consisting of a poorly sorted consolidated mixture of ash and pumice with local occurrences of angular lithic fragments of older volcanic rocks, limestone and brick. The volcanological stratigraphy at Herculaneum is detailed in ref. 7 . The ash and pumaceous matrix is represented by samples $\mathrm{H} 1$ to $\mathrm{H} 4$; a variety of lithic fragments in addition to a large piece of light-coloured pumice, all between 10 and $20 \mathrm{~cm}$ in largest dimension, are represented by samples $\mathrm{H} 5$ to $\mathrm{H} 10$ (Table 1 ). The samples were taken over a stratigraphic interval of $\sim 2 \mathrm{~m}$, starting $\sim 1 \mathrm{~m}$ above the excavation floor.
Most of the directions of the sample natural remanent magnetization (NRM) (Fig. 1a) group near to the present geomagnetic field for the site locality but four of the six samples of lithic fragments give divergent and scattered directions. The NRM intensities and Konigsberger values (ratio of remanent magnetization to magnetization induced in present geomagnetic field) show only small variation amongst the samples of matrix but are more variable for the samples of lithic fragments (Table 1). In all samples, however, the remanent magnetizations exceed the induced components by anything between a factor of 4 and a factor of 69 .

Progressive thermal demagnetization experiments show that the NRM of the the matrix samples consists of a single stable component similar in direction to the present orientation of the geomagnetic field and which persists up to demagnetization temperatures of $550^{\circ} \mathrm{C}$, when it disappears (Fig. 2a). In contrast, the NRM of all six lithic fragments is the result of two components of magnetization: $\mathrm{A}$ and $\mathrm{B}$. The $\mathrm{A}$ component is identified in the initial stages of thermal demagnetization up to temperatures of $350-400^{\circ} \mathrm{C}$. The $\mathrm{B}$ component is the magnetization remaining in the final stages of thermal demagnetization, up to temperatures between 550 and $600{ }^{\circ} \mathrm{C}$ when the magnetization of the samples disappears (Fig. $2 b, c$ ). The directions of the A and B component (Fig. 1b, $c$ and Table 1) in each lithic fragment sample are readily determined by regression analysis on the linear segments of the orthogonal vector end point demagnetization diagrams, as shown in Fig. 2. Where two specimens could be obtained for measurement from a drill-core sample of a lithic clast, both specimens provided similar magnetic characteristics.

The mean direction of the A component from the six lithic samples is $\operatorname{dec}=359.2^{\circ}$, inc $=56.8^{\circ}, \alpha_{95}=4.2^{\circ}$ and is statistically indistinguishable from the mean direction of the matrix samples (Table 1) or from the present geomagnetic field direction ( $\mathrm{dec}=$ $359^{\circ}$, inc $=55^{\circ}$ ). Although the $\mathrm{B}$ components are well characterized and show good stability in individual lithic clasts, as a group they are randomly distributed at the $95 \%$ level of confidence (Table 1).

The lithic fragments evidently possessed a remanent magnetization before their incorporation in the pyroclastic deposit. This magnetization is now preserved as component $B$ and may have originated as a thermal remanence (TRM) during initial cooling of the basalt and pumice, possibly a detrital remanence during initial deposition of the limestone, and either

Table 1 Palaeomagnetic measurements on pyroclastic samples from Herculaneum

\begin{tabular}{|c|c|c|c|c|c|c|}
\hline \multirow{2}{*}{$\begin{array}{l}\text { a Matrix samples } \\
\text { Sample }\end{array}$} & \multicolumn{4}{|c|}{ NRM } & \multicolumn{2}{|c|}{$4000^{\circ} \mathrm{C}$} \\
\hline & $J\left(10^{-4} \mathrm{G}\right)$ & $Q$ & dec & inc & dec & inc \\
\hline $\begin{array}{l}\mathrm{H} 1 \\
\mathrm{H} 2 \\
\mathrm{H} 3 \\
\mathrm{H} 4\end{array}$ & $\begin{array}{l}3.4 \\
3.2 \\
3.1 \\
3.4 \\
\quad \mathrm{Mea}\end{array}$ & $\begin{array}{l}5.8 \\
5.9 \\
5.2 \\
5.6\end{array}$ & $\begin{array}{c}355^{\circ} \\
353^{\circ} \\
1^{\circ} \\
357^{\circ} \\
356.4^{\circ} \\
(K=1,\end{array}$ & $\begin{array}{l}55^{\circ} \\
56^{\circ} \\
59^{\circ} \\
56^{\circ} \\
56.5^{\circ} \\
\left.2.9^{\circ}\right)\end{array}$ & $\begin{array}{l}351^{\circ} \\
349^{\circ} \\
355^{\circ} \\
355^{\circ} \\
352.5^{\circ} \\
(K=18\end{array}$ & $\begin{array}{l}50^{\circ} \\
62^{\circ} \\
52^{\circ} \\
59^{\circ} \\
55.8^{\circ} \\
6.7^{\circ}\end{array}$ \\
\hline
\end{tabular}

$b$ Lithic clasts

\begin{tabular}{|c|c|c|c|c|c|}
\hline \multirow[b]{2}{*}{ Sample } & \multirow[b]{2}{*}{ Composition } & \\
\hline & & $J\left(10^{-4} \mathbf{G}\right)$ & $Q$ & dec & inc \\
\hline H5 & Pumice & 2.4 & 4.1 & $245^{\circ}$ & $73^{\circ}$ \\
\hline H6 & Basalt & 7.5 & 15 & $285^{\circ}$ & -8 \\
\hline H7 & Basalt & 10 & 14 & $259^{\circ}$ & $37^{\circ}$ \\
\hline H8 & Limestone & 3.5 & 69 & $358^{\circ}$ & $53^{\circ}$ \\
\hline H9 & Limestone & 3.8 & 64 & $359^{\circ}$ & $61^{\circ}$ \\
\hline \multirow[t]{2}{*}{ H10 } & Brick(?) & 15 & 23 & $309^{\circ}$ & $36^{\circ}$ \\
\hline & \multicolumn{3}{|c|}{ Means $(n=6)^{*}$} & $300.6^{\circ}$ & $49.9^{\circ}$ \\
\hline
\end{tabular}

Component $\mathrm{A}$

\begin{tabular}{cc}
\hline dec & inc \\
$9^{\circ}$ & $56^{\circ}$ \\
$353^{\circ}$ & $55^{\circ}$ \\
$356^{\circ}$ & $52^{\circ}$ \\
$6^{\circ}$ & $61^{\circ}$ \\
$359^{\circ}$ & $61^{\circ}$ \\
$354^{\circ}$ & $55^{\circ}$ \\
$359.2^{\circ}$ & $56.8^{\circ}$ \\
$\left(K=251, \alpha_{95}=4.2^{\circ}\right)$ \\
$r=5.98$
\end{tabular}

Component B

\begin{tabular}{cr}
\hline dec & inc \\
$199^{\circ}$ & $53^{\circ}$ \\
$259^{\circ}$ & $-38^{\circ}$ \\
$238^{\circ}$ & $4^{\circ}$ \\
$226^{\circ}$ & $-66^{\circ}$ \\
$184^{\circ}$ & $-61^{\circ}$ \\
$286^{\circ}$ & $15^{\circ}$ \\
$240.1^{\circ}$ & $-19.9^{\circ}$ \\
$\left(K=2, \alpha_{95}=59^{\circ}\right)$ \\
$r=3.75$
\end{tabular}

$J$ is intensity of magnetization; $Q$ is Konigsberger ratio; dec, inc, are declination, inclination of magnetization; means and statistics calculated using ref. 13; test for randomness from ref. 14.

*For $n=6$, distribution is random if $r<3.85$. 
Fig. 2 Orthogonal projections of the successive end points of the magnetization vector (method from ref. 15) during progressive thermal demagnetization of representative samples from Herculaneum pyroclastic deposit. Solid symbols represent projection on the horizontal plane, open symbols on the north-south vertical plane. $a$, Matrix sample; $b$, basalt clast; $c$, limestone clast. Dashed lines in $b, c$ are linears segments corresponding to A or B components.
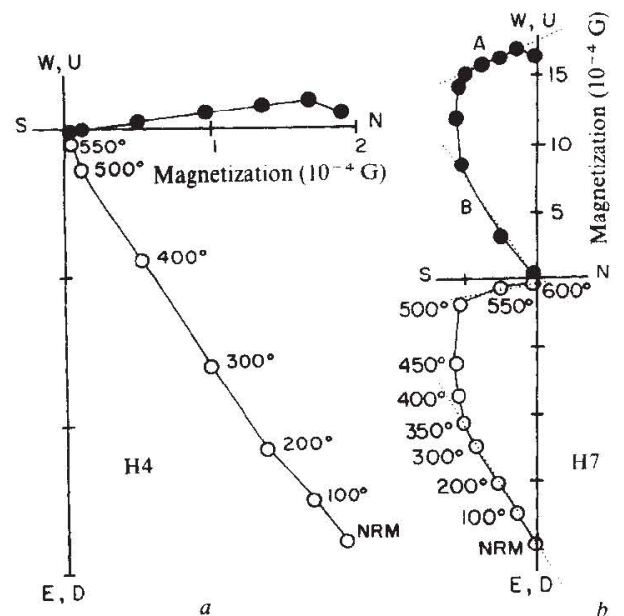

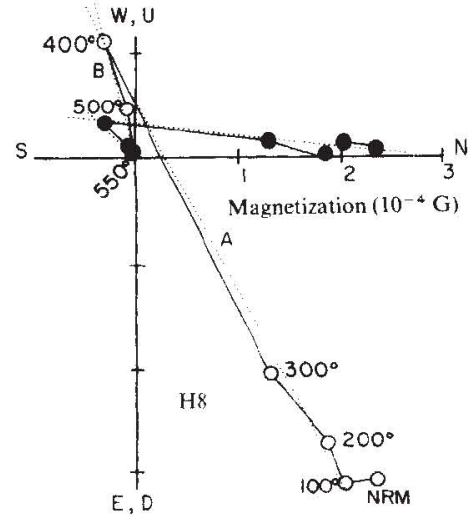

This consistency over the various lithologies supports acquisition of a partial TRM at a common temperature and against elevation of blocking temperatures by other processes, for example, viscous magnetization or magnetochemical alteration. On the other hand, emplacement temperatures higher than $400^{\circ} \mathrm{C}$ would have more completely reset the $\mathrm{B}$ component magnetization.

The fact that our maximum temperature estimate coincides closely with Maury's minimum temperature estimate strongly suggests that the emplacement temperature of the AD 79 Herculaneum pyroclastic deposit sampled was indeed close to $400{ }^{\circ} \mathrm{C}$. The deposits can therefore be considered as largely ignimbrites (hot pyroclastic flows) which in general had not attained sufficiently high temperatures to cause pervasive welding. Other evidence for a high emplacement temperature includes the occurrence of vertical lithic-rich pipes, interpreted as degassing structures, and typical fine-grained ignimbrite basal layers to individual flow units ${ }^{2-5}$.

The matrix samples give only a single magnetization component which is similar in direction to the A component of the lithic clasts although the unblocking temperatures extend to $550-660^{\circ} \mathrm{C}, \sim 200^{\circ} \mathrm{C}$ higher than for component A. Given the close proximity of the sampling sites for the matrix and clast samples, it is unlikely that the higher maximum unblocking temperatures observed for the matrix material reflects a correspondingly higher emplacement temperature than indicated by the clast magnetizations. The unblocking temperature spectra of the matrix samples moreover are not consistent with the spectrum of a TRM produced by cooling a matrix sample from $600^{\circ} \mathrm{C}$ in the Earth's field (Fig. 3). The NRM of the matrix material is therefore more likely to contain a contribution from a magnetization besides a partial TRM from $400{ }^{\circ} \mathrm{C}$, perhaps a detrital remanence which, from the similarity in direction, was also acquired during emplacement of the pyroclastic deposit but which is typically carried by a grain assemblage with a wide distribution of blocking temperatures. Thus while bulk samples of the matrix may provide a valid record of geomagnetic field orientation corresponding to the time the deposits are formed, they are not as such readily useful for emplacement temperature determination.

Palaeomagnetic techniques have been used to discriminate hot and cold emplacement of pyroclastic deposits, for example, in $\operatorname{Japan}^{8}$, Santorini ${ }^{9}$ and the western US ${ }^{10}$. The Herculaneum pyroclastic flow can be categorized as a type III deposit (emplaced below their maximum blocking temperature but above the ambient temperatures) of Hoblitt and Kellogg ${ }^{10}$, of which they found no example. As palaeomagnetic techniques for emplacement temperature estimation depend largely on the common occurrence of magnetizable materials in pyroclastic deposits, the techniques should be of particular value in estimating emplacement temperatures of unwelded pyroclastic flow

units in which lithological evidence for heating is ambiguous, as
Fig. 3 Fraction of magnetization remaining with progressive thermal demagnetization for the NRM, and for a TRM produced by cooling from $600^{\circ} \mathrm{C}$ in the Earth's magnetic field, of a sample of pyroclastic matrix from Herculaneum. 
at Herculaneum. The size range of lithic fragments suitable for such experiments can be extended downward for example, to matrix components, by use of microanalytical techniques ${ }^{11,12}$ while unblocking temperature profiles through very large lithic clasts may provide additional information on the thermal history of the pyroclastic deposit. Moreover, estimates of maximum emplacement temperature by the magnetic method, which are possible up to the Curie point of the constituent magnetic mineral (for example, $585^{\circ} \mathrm{C}$ for magnetite) can extend the range of temperature estimates obtained from studies of organic matter, which appear to be most definitive from $100^{\circ} \mathrm{C}$ to $\sim 350^{\circ} \mathrm{C}$ (ref. 6).

We thank Doris Lafferty for laboratory magnetic measurements. Work was supported in part by NSF grant EAR79. 09985 to D.V.K. and D.N. Lamont-Doherty Geological Observatory contribution 3114 .

1. Maiuri, A. Scient. Am. 198, 68 (1958); Herculaneum (Rome 1977)

2. Merrill, E. T. Am. J. Archeol. 22, 304 (1918); 24, 262 (1920).

3. Sparks, R. S. J. \& Walker, G. P. L. Nature 241, ó2 (1973).

Sparks, R. S. J., Self, S. \& Walker, G. P. L. Geology 1, 115 (1973)

Sparks, R. S. J. New Scient. 59, 134 (1973).

Maury, R. C. Bull. Centre Rech. Pan-SNPA 10, 289 (1976)

Sirro

Sigurdsson, H., Cashdollar, S. \& Sparks, R. S. J. Am. J. A

Aramaki, S. \& Akimoto, S. I, Am. J. Sci. 25s,
Wright, J. V. Bull. volcan. 41, 131 (1978).

0. Hoblitt, R. P. \& Kellogg, K. S. Bull. geol. Soc, Am. 90, 633 (1979)

1. Wu, Y, T., Fuller M. \& Schmidt, V. A. Earth planet. Sci. Lett. 23, 275 (1974).

. Van der Voo, R. \& Geissman, J. W. EOS 59, 1060 (1978).

Fisher, R. A. Proc. R. Soc. A217, 295 (1953).

14. Watson, G. S. Mon. Not. R. ast. Soc., Geophys. Suppi. 7, 160 (1956).

15. Zijderveld, J. D. A. in Methods in Palaeomagnetism, 254 (Elsevier, Amsterdam 1967).

\section{Petrogenesis of Andean andesites from combined $\mathrm{O}-\mathrm{Sr}$ isotope relationships}

\section{Russell S. Harmon}

Isotope Geology Unit, Scottish Universities Research and Reactor Centre, East Kilbride G75 0QU, UK

\section{Richard S. Thorpe \& Peter W. Francis}

Department of Earth Sciences, The Open University, Milton Keynes MK7 6AA, UK

The descent of the oceanic Nazca plate below the western margin of South America is responsible for the seismicity, tectonism and magmatism characteristic of Andean-type continental margins. Within this geological setting there is much debate concerning the petrogenesis of the calc-alkaline volcanic association. A thermal model for the descent of oceanic below continental lithosphere suggests that melting of subducted oceanic crust, the asthenospheric mantle wedge, and the lower crust might occur ${ }^{1}$, and hence calc-alkaline volcanic rocks erupted at the surface in such regions might be derived from one or more of these sources. In the Andes, for example, Pichler and Zeil ${ }^{2}$ have invoked partial melting of lower continental crust, while others ${ }^{3-5}$ envisage petrogenesis of andesites from subcrustal mantle sources possibly in conjunction with crustal contamination $^{6-9}$. We present here new 0 -isotope data for volcanic rocks from three contrasted volcanic settings in Ecuador, north Chile, and north-west Argentina. We then consider the significance of observed $\mathbf{O}-$ Sr isotope relationships, and attempt to evaluate the important factors in the petrogenesis of Andean andesitic lavas.
Active volcanism in the Andes occurs in three distinct regions: a northern zone $\left(5^{\circ} \mathrm{N}-2^{\circ} \mathrm{S}\right)$, a central zone $\left(16-28^{\circ} \mathrm{S}\right)$, and a southern zone $\left(33-52^{\circ} \mathrm{S}\right)$; each having andesitic associations with distinctive chemical and isotopic compositions. The volcanic centres selected for study are in the northern and central volcanic zones. The northern zone in Ecuador and Columbia consists of composite volcanoes composed predominantly of basaltic andesite built on a $40-50-\mathrm{km}$ thick sialic crust ${ }^{10,11}$. Its sub-volcanic basement consists of metamorphic rocks of Cretaceous or older age ${ }^{12}$. The central zone is characterized by composite volcanoes and large-volume ignimbrite sheets which overlie a thicker and more ancient sialic crust. Although the oldest rocks exposed adjacent to the active volcanic belt in southern Peru and northern Chile are Palaeozoic, Precambrian rocks occur to the west on the Perıvian coast ${ }^{13}$ and to the east below the Bolivian altiplano ${ }^{14,15}$ suggesting that the central volcanic belt is underlain by Prerambrian rocks ${ }^{16}$. It has also been argued ${ }^{17}$ that the crust in the central Andes nearly doubled in thickness in the Cenozoic, so that the volcanoes of north Chile and south Peru rest on the central keel of the Andes where the crust is $\sim 70 \mathrm{~km}$ thick. The volcanic setting in north-west Argentina is different to that to the west in southern Peru and northern Chile-here volcanic rocks occur on the 'Pampean Ranges' massif, a 'basin-and-range' province which comprises a wide variety of granitic and metamorphic rocks ${ }^{18}$ for which data indicate a late Precambrian to early Palaeozoic age ${ }^{19}$.

The Tertiary and Quaternary volcanic rocks of the Andes fall within the basaltic andesite-andesite-dacite classification of Peccerillo and Taylor ${ }^{20}$. Chemical and isotopic compositions vary systematically across the Andean orogenic belt with $\mathrm{SiO}_{2}$, $\mathrm{K}_{2} \mathrm{O}$ and $\left({ }^{87} \mathrm{Sr} /{ }^{86} \mathrm{Sr}\right)_{i}$ increasing from west to east ${ }^{9,21-24}$ with calc-alkaline lavas generally enriched in $\mathrm{K}, \mathrm{Rb}$ and $\mathrm{Sr}$ relative to $\mathrm{P}, \mathrm{Nb}, \mathrm{Nd}, \mathrm{Zr}$ and $\mathrm{Ti}$ (refs 9,25 ). There are, however, important inter-regional differences. The Ecuadorian lavas are olivinepyroxene-bearing basaltic andesites with $53-61 \% \mathrm{SiO}_{2}, 1.1-$ $2.2 \% \mathrm{~K}_{2} \mathrm{O}, 492-1,144$ p.p.m. Sr, and 19-65 p.p.m. Rb (refs 7, $26,27)$ whereas the lavas of north Chile and South Peru are predominantly pyroxene-hornblende-bearing andesites and

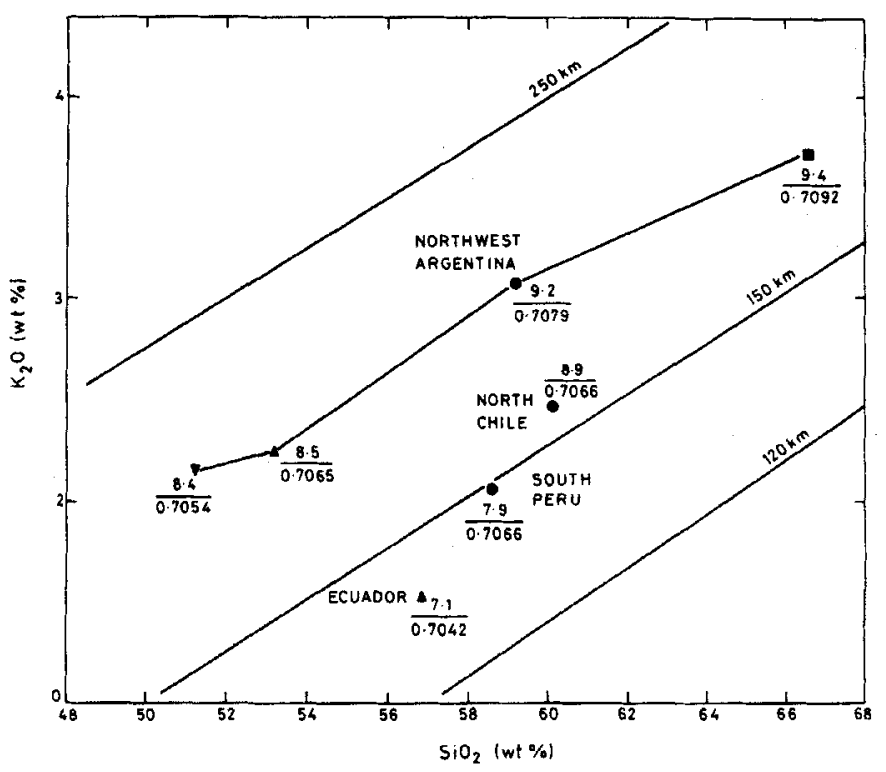

Fig. 1 Mean $\mathrm{K}_{2} \mathrm{O}$ contents plotted against $\mathrm{SiO}_{2}$ for volcanic centres in Ecuador, north Chile, south Peru, and north-west Argentina. The numbers shown by each data point are the average ${ }^{18} \mathrm{O} /{ }^{16} \mathrm{O}$ (upper) and ${ }^{87} \mathrm{Sr} /{ }^{86} \mathrm{Sr}$ (lower) ratios. The lines labelled 120,150 and $250 \mathrm{~km}$ are inferred contours to the depth of the seismic zone ${ }^{33}$. $\boldsymbol{\nabla}$, Basalt; $\boldsymbol{\Lambda}$, basaltic andesite; $\boldsymbol{\theta}$, andesite; $\boldsymbol{\square}$, dacite. 